\title{
ANÁLISIS QUÍMICO DE PINTURAS EN ALFARERÍAS DE ESTILO GOYA-MALABRIGO (NORDESTE DE ARGENTINA)
}

\author{
CHEMICAL ANALYSIS OF PAINT FOUND ON GOYA-MALABRIGO STYLE \\ POTTERY (NORTHEAST ARGENTINA)
}

Flavia Ottalaganoa, María Reinosob \& Eleonora Freire ${ }^{c}$

En este artículo se presentan los resultados obtenidos a partir de la aplicación combinada de espectroscopía Raman (RS), difracción de rayos-X (XRD), microscopía electrónica de barrido y microanálisis por dispersión de energía de rayos-X (sEMEDX) para el estudio composicional de pinturas en alfarerías de estilo Goya-Malabrigo. Las muestras proceden de sitios prehispánicos de la cuenca del río Paraná, localizados en la provincia de Entre Ríos, al nordeste de Argentina. En las pinturas rojas se detecta la utilización de hematita y maghemita mientras que, en las pinturas blancas, se evidencia el empleo de hidroxiapatita como pigmento principal.

Palabras clave: Pinturas, Análisis Químicos, Cerámica Arqueológica, Estilo Goya-Malabrigo, Cuenca del Río Paraná.

This article presents the results obtained from a compositional study of paint found on ceramic pieces of the Goya-Malabrigo style through the combined application of Raman spectroscopy (RS), X-ray diffraction (XRD), and scanning electronic microscopy/ energy-dispersive $x$-ray microanalysis (SEM-EDX). The samples are from pre-Hispanic sites in the Paraná River basin, in Entre Ríos province, northeast Argentina. The analyses detected hematite and maghemite in the red paintings and hydroxyapatite as the main pigment in the white paintings.

Keywords: Paintings, Chemical Analyses, Archeological Ceramics, Goya-Malabrigo Style, Paraná River Basin.

\section{INTRODUCCIÓN}

El estilo Goya-Malabrigo es representativo de los grupos humanos prehispánicos que ocuparon la cuenca fluvial del Paraná medio y parte del Paraná inferior, y es reconocible también en algunos tramos del río Uruguay y costa uruguaya del río de La Plata (Ceruti 2003). La elaboración de asas figurativas constituye uno de sus aspectos centrales. El motivo más recurrente es, sin duda, la representación de cabezas de aves psitaciformes o "cabezas de loro" (Serrano 1946, 1958; González 1977; Caggiano 1984; Rodríguez 1992; Ceruti 2003). Estas asas han formado parte de vasijas de morfologías y tamaños variados, entre las que se incluyen las denominadas "alfarerías gruesas" (Serrano 1958), conocidas también como "campanas" (Gaspary 1950).

Las alfarerías gruesas, cuya funcionalidad aún no ha podido ser precisada, son consideradas igualmente propias del estilo cerámico Goya-Malabrigo. Son piezas muy peculiares ya que presentan, entre otras características, una forma ligeramente acampanada, paredes

A Flavia Ottalagano, CONICET/Instituto Nacional de Antropología y Pensamiento Latinoamericano, Buenos Aires, Argentina. E-mail: flaviaott7@gmail.com

B María Reinoso, conicet/Universidad Nacional de San Martín/Comisión Nacional de Energía Atómica, Buenos Aires, Argentina. E-mail: reinoso@tandar.cnea.gov.ar

c Eleonora Freire, conicet/Universidad Nacional de San Martín/Comisión Nacional de Energía Atómica, Buenos Aires, Argentina. E-mail: elefreire@gmail.com 


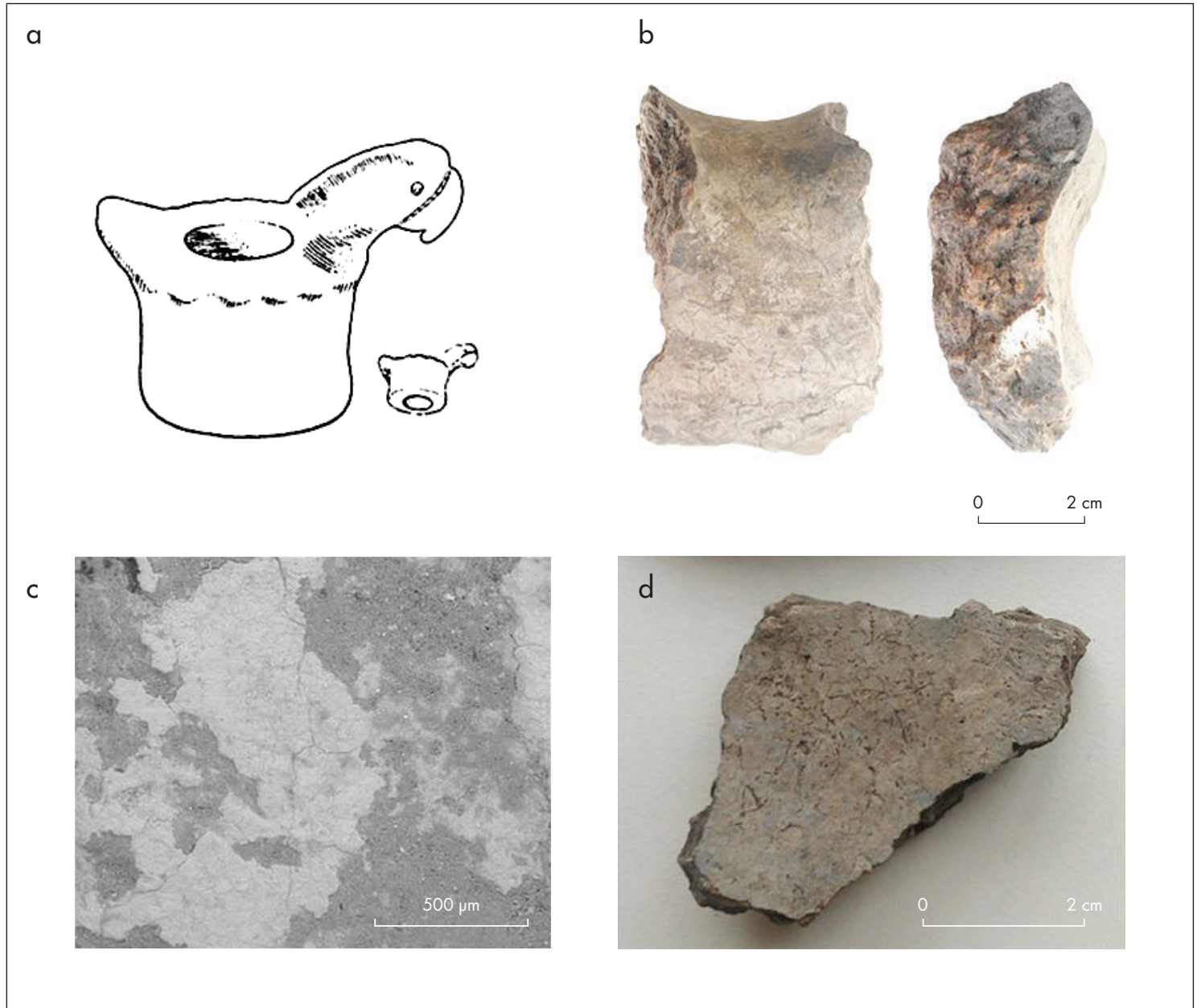

Figura 1. Ejemplos de "alfarerías gruesas" y pintura blanca: a) reconstrucción de "alfarería gruesa” (tomado y modificado de Serrano 1946: 58); b) borde de "alfarería gruesa" con pintura blanca externa; c) fotomicrografía mediante sEM de superficie pintada (tomado de Ottalagano et al. 2015a); d) fragmento de recipiente "no campana" con pintura blanca interna. Figure 1. Examples of "thick-walled" ceramics and white paint: $a)$ reconstruction of "thick-walled" ceramic piece (modified from Serrano 1946: 58); $\boldsymbol{b}$ ) lip of a "thick-walled" ceramic piece with white exterior paint; $c$ ) SEM photomicrograph of the painted surface (taken from Ottalagano et al. 2015a); d) sherd of a "non-bell-shaped" vessel with white interior paint.

extremadamente gruesas y, al menos, dos aberturas: una superior y otra basal (fig. 1a). Algunas de estas exhiben una pintura blanca, que generalmente recubre la totalidad de su superficie externa (fig. 1b-c). La presencia de pintura blanca se ha constatado también, en muy escasa proporción, en recipientes que no pertenecen a esta morfología (fig. 1d).

El repertorio cerámico Goya-Malabrigo incluye también vasijas decoradas con pintura roja, las cuales se corresponden mayoritariamente con recipientes abiertos, como cuencos, escudillas y platos (Ottalagano 2013a, 2013b). Comúnmente, la misma se aplicó en la parte interna de los recipientes, coloreando la superficie en su totalidad o bien trazando motivos geométricos (fig. 2). El diseño más frecuente suele ser la realización de una o varias franjas pintadas dispuestas de manera paralela a la línea del borde. Asimismo, es común la utilización de pintura roja para colorear vasijas que presentan decoración incisa y figurativa.

Una pintura se define generalmente como una mezcla basada en al menos dos componentes. Uno de ellos es el pigmento o el material colorante y el otro, las sustancias utilizadas como aglutinante y carga, las que pueden ser coloras o incoloras (Petit \& Valot 1991). Esta 
a

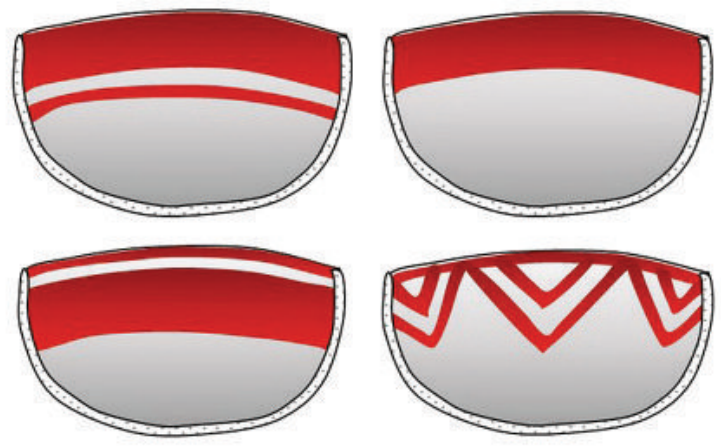

b

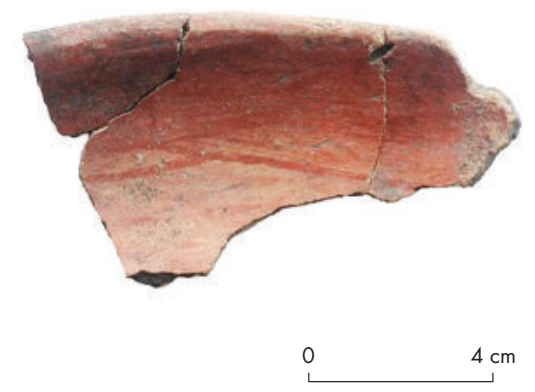

Figura 2. Motivos decorativos con pintura roja: a) sección interna de recipientes con diseños pintados (basado en Serrano, 1946: 54); b) fragmento de recipiente con pintura interna del sitio AAI. Figure 2. Motifs decorated with red paint: a) cross-sections of the vessel interiors with painted designs (based on Serrano, 1946: 54); $b$ ) sherd of a vessel from site AAI showing interior paint.

mezcla de sustancias puede ser aplicada antes o después de la cochura de las piezas (Rye 1981). En consecuencia, la línea de separación entre las pinturas pre-cocción y los engobes se vuelve muy sutil, ya que se reconoce que algunas variantes de la técnica de engobe implican el agregado de algún material colorante al fluido arcilloso que lo conforma (Shepard 1963, Convención Nacional de Antropología 1966, García Rosselló \& Calvo Trías 2013). También se ha propuesto utilizar la denominación de cobertura para hacer referencia a aquellos acabados de superficie que exhiben color, pero que muestran dificultades para poder identificarlos como engobe o como pintura, especialmente por el tamaño reducido de los tiestos ${ }^{1}$ (Babot \& Apella 2007, Frère 2015).

El estudio composicional de las pinturas utilizadas en la decoración cerámica ha ido avanzando considerablemente en la arqueología argentina, especialmente en la región del Noroeste Argentino, donde la alfarería es muy abundante en el registro arqueológico (por ej., Botto et al. 1998, Zagorodny et al. 2002, Cremonte et al. 2003, Babot \& Apella 2007, Bertolino et al. 2009, De la Fuente et al. 2010, Palamarczuk \& Fernández de Rapp 2011, Acevedo et al. 2012, Bugliani et al. 2012, López et al. 2012, Marte et al. 2012, Aldazabal et al. 2014, Freire et al. 2016). En Pampa y Patagonia se ha utilizado particularmente la difracción de rayos-X para la determinación composicional de las materias primas colorantes (Barbosa \& Gradin 1986-1987, Porto López
\& Mazzanti 2009, Matarrese et al. 2011, Pedrotta 2011) y de las pinturas rupestres (Rial \& Barbosa 1983-1985), así como para la caracterización mineralógica de las alfarerías (Gómez Otero et al. 1996, Bouza et al. 2007, Schuster 2010).

Específicamente en la arqueología de la cuenca Paraná-Plata, se han realizado análisis de la fracción inorgánica de pinturas rojas y blancas empleadas en la decoración cerámica y de la fracción orgánica de residuos de pigmentos hallados en estratigrafía, mediante técnicas como fluorescencia de rayos-X, difracción de rayos-X, espectrometría Raman y cromatografía gaseosa acoplada a espectrometría de masa (GC-MS) (González de Bonaveri \& Frère 2002, 2004, González 2005, Paleo \& Pérez Meroni 2009, Frère 2015). En relación con los tramos más septentrionales de la cuenca Paraná-Plata, se registra el estudio de pinturas en cerámicas prehispánicas del Paraná inferior a través de la técnica SEM-EDX (microscopia electrónica de barrido y microanálisis por dispersión de energía de rayos-X) (Pérez et al. 2015), así como el análisis de engobes y pastas por medio de XRD y SEM-EDX, igualmente en sitios ubicados en el Paraná inferior (Tapia et al. 2013). Con respecto al estudio de las pinturas asociadas al estilo Goya-Malabrigo, los primeros datos se recabaron por medio de la técnica SEM-EDX, considerando muestras procedentes de los sitios La Palmera II y v, Arroyo Arenal I, Puerto Cuartel I, Arroyo El Largo I y Cerro Puesto Acosta (Ottalagano et al. 2015a). 
El objetivo de este trabajo es el estudio composicional de las pinturas rojas y blancas del repertorio cerámico Goya-Malabrigo. Para ello se analizaron mediante técnicas físico-químicas diez fragmentos pintados procedentes de cuatro sitios arqueológicos ubicados en distintos tramos de la cuenca media e inferior del río Paraná. Teniendo en cuenta la cuantificación de los bordes hallados, la decoración a base de pintura roja se presenta en promedio en un $15 \%$ de las vasijas recuperadas en estos sitios, en tanto que aproximadamente solo un $2 \%$ de los recipientes exhibe pintura blanca, los cuales se corresponden mayoritariamente con artefactos "campana".

Las muestras seleccionadas se asocian a una cronología de entre los $1380 \pm 100$ (cal. 527-882 AD, 2 sigma, $\mathrm{p}=0,92$ ) y los $488 \pm 24$ años AP (cal. 1419-1464 AD, 2 sigma, $\mathrm{p}=0,98$ ) (ver apartado siguiente). El análisis petrográfico de varios de los fragmentos cerámicos considerados aquí permitió identificar pastas con tiestos molidos y con inclusiones minerales que están naturalmente presentes en los bancos sedimentarios locales -tales como cuarzo, feldespatos y óxidos férricos-, lo que sugiere la manufactura local de esta cerámica (Ottalagano 2013a, $2015,2016 a)$. La presencia de pequeñas masas amorfas de arcilla cocida recuperadas durante la excavación de los sitios La Palmera II, Cerro Puesto Acosta y Arroyo Arenal I (Ceruti 1989, Ottalagano et al. 2010, 2015b, Ottalagano 2016b) es indicadora igualmente de la elaboración in situ de esta alfarería.

En esta oportunidad, se presenta información cualitativa obtenida por medio de dos técnicas analíticas: espectroscopía Raman y difracción de rayos-X, la cual se discute en relación con los datos recabados previamente mediante microscopía electrónica de barrido y microanálisis por dispersión de energía de rayos-X. Este conjunto de técnicas arqueométricas no destructivas, que se suelen aplicar de manera combinada, constituyen una herramienta efectiva para evaluar las materias primas que se utilizaron en el pasado para la elaboración de las pinturas.

\section{MATERIALES Y MÉTODOS}

Las muestras de pintura analizadas en este trabajo proceden de tiestos cerámicos que fueron recuperados en cuatro sitios arqueológicos multipropósito emplazados en la cuenca del río Paraná, en la provincia de Entre Ríos, al noreste de Argentina (fig. 3). La alfarería proveniente de Arroyo Largo I (ALI) fue obtenida por Ceruti (1989), mientras que la de los sitios Cerro Puesto Acosta (CPA), La Palmera II (LPII) y Arroyo Arenal I (AAI) por Ottalagano y colaboradores (Ottalagano et al. 2010, 2015b, Ottalagano 2016b).

Los sitios arqueológicos mencionados se ubican temporalmente dentro del tramo final del Holoceno tardío. Del sitio AAI se obtuvieron dos dataciones: una de $488 \pm 24$ años ${ }^{14} \mathrm{C}$ AP sobre restos Myocastor coypus (AA108377) y otra de $625 \pm 46$ años ${ }^{14} \mathrm{C}$ AP sobre restos humanos (AA102684). Las mismas indican una ocupación tardía, cercana al contacto europeo (Ottalagano 2016b). El sitio LPII presenta dos fechados: uno de 1056 \pm 47 años ${ }^{14} \mathrm{C}$ AP sobre restos humanos (AA102683) y otro de $1032 \pm 47$ años ${ }^{14} \mathrm{C}$ AP sobre restos de coipo (AA102682) (Ottalagano et al. 2015b). Por último, el sitio ALI registra dos dataciones de $900 \pm 120$ años ${ }^{14} \mathrm{C}$ AP y de $1380 \pm 100$ años ${ }^{14} \mathrm{C}$ AP, ambas sobre restos de carbón (Ceruti 2003).

Se analizaron diez fragmentos cerámicos con pinturas pre-cocción blancas y rojas (tabla 1). Los mismos fueron hallados en estratigrafía y proceden de contextos domésticos. Cabe señalar que las denominadas aquí genéricamente como pinturas blancas, pueden llegar a presentar tonos levemente grisáceos o incluso ligeramente crema, como se especifica en la tabla 1 considerando el código Munsell (1994). Las pinturas rojas estudiadas exhiben una tonalidad roja intensa, con excepción de la muestra 9 que presenta una coloración rojo marrón (tabla 1).

Cuatro de los tiestos seleccionados forman parte de "alfarerías gruesas" o "campanas" (sensu Gaspary 1950, Serrano 1958). En relación con la muestra 5, no pudo establecerse con certeza si perteneció efectivamente a uno de estos artefactos por tratarse de un fragmento de cuerpo (tabla 1). Las muestras restantes corresponden a otras morfologías que no pudieron ser precisadas en detalle, por tratarse igualmente de fragmentos de cuerpo o bien de bordes muy pequeños. Además, son poco representativas para permitir la reconstrucción de la vasija. Sin embargo, dada la presencia en estos casos de pintura interna, es posible que se correspondan con recipientes abiertos, tales como cuencos y escudillas, los cuales se registran con una alta frecuencia, especialmente entre las vasijas con pintura roja de los sitios ALI, LPII, AAI y CPA (Ottalagano 2013a, 2013b).

Para realizar el estudio composicional de las pinturas se utilizó espectroscopía Raman y difracción de rayos-X. Ambas técnicas proporcionan información sobre las 


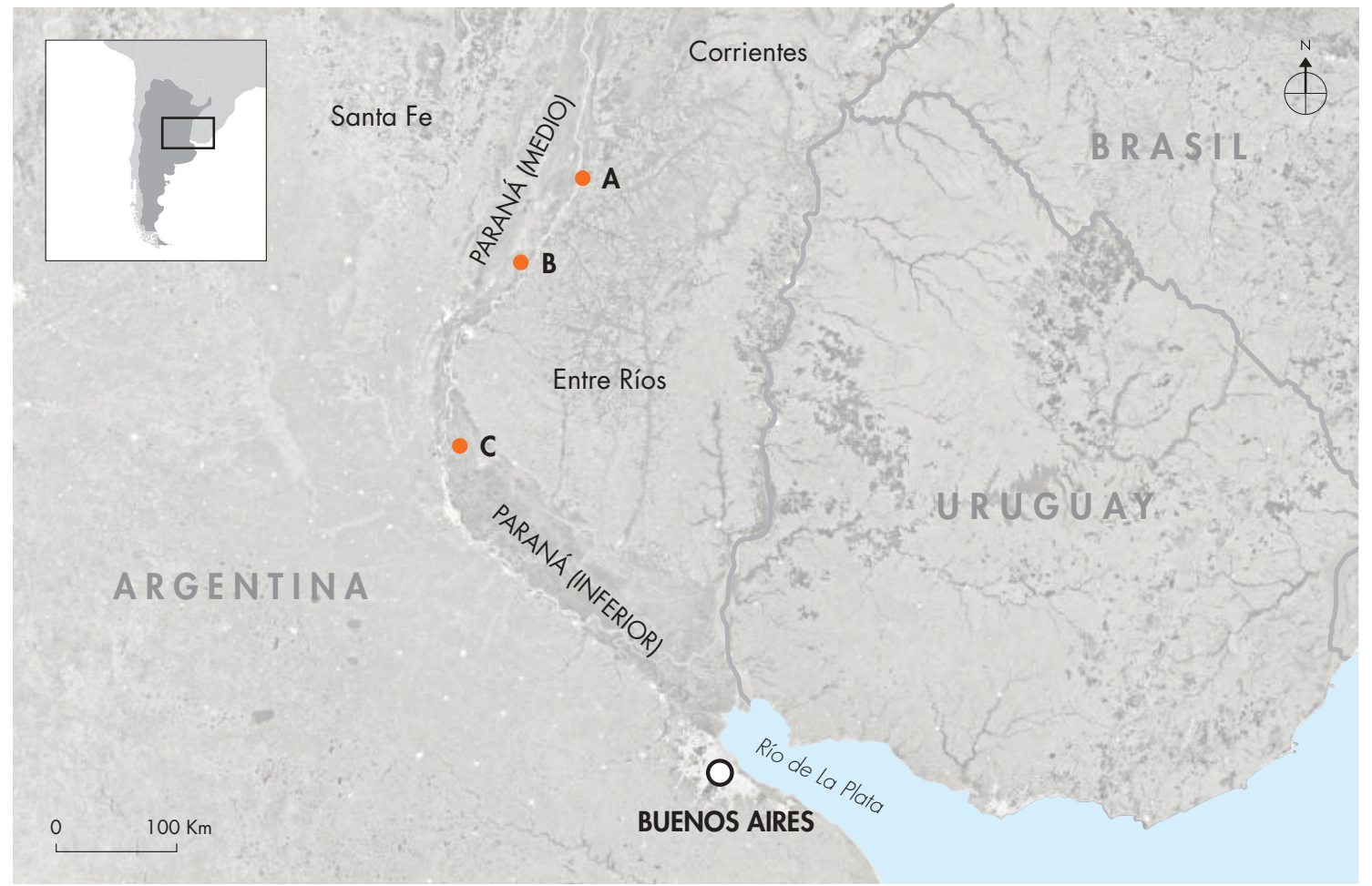

Figura 3. Localización de los sitios arqueológicos considerados: a) sitios AAI y ALI (Paraná medio); b) sitio LPII (Paraná medio); c) sitio CPA (Paraná inferior). Figure 3. Location of the archeological sites referred to herein: $\boldsymbol{a})$ sites AAI and ALI (middle Paraná); $\boldsymbol{b})$ site LPII (middle Paraná); c) site CPA (lower Paraná).

Tabla 1. Descripción de las muestras de pintura. Table 1. Description of paint samples.

\begin{tabular}{|c|c|c|c|c|c|}
\hline MUESTRA & COLOR & $\begin{array}{l}\text { CÓDIGO } \\
\text { MUNSELL }\end{array}$ & $\begin{array}{c}\text { SITIO } \\
\text { ARQUEOLÓGICO }\end{array}$ & $\begin{array}{l}\text { ALFARERIA } \\
\text { GRUESA }\end{array}$ & $\begin{array}{l}\text { LOCALIZACIÓN } \\
\text { EN LA VASIJA }\end{array}$ \\
\hline 1 & blanca & 7,5 YR $8 / 2$ & $\mathrm{CPA}$ & sí & externa \\
\hline 2 & blanca & 10 YR 8/1 & AAI & no & interna \\
\hline 3 & blanca & 10 YR $7 / 3$ & LPII & sí & externa \\
\hline 4 & blanca & 7,5 YR $8 / 2$ & AAI & sí & externa \\
\hline 5 & blanca & 2,5 Y $8 / 3$ & AAI & indeterminado & externa \\
\hline 6 & blanca & 7,5 YR $8 / 2$ & LPII & sí & externa \\
\hline 7 & roja & $10 \mathrm{R} 4 / 8$ & AAI & no & interna \\
\hline 8 & roja & $10 \mathrm{R} 4 / 6$ & ALI & no & interna \\
\hline 9 & roja & 5 YR 5/4 & AAI & no & interna \\
\hline 10 & roja & $10 \mathrm{R} 4 / 8$ & AAI & no & interna \\
\hline
\end{tabular}


sustancias inorgánicas presentes en las pinturas. No requieren una preparación especial de las muestras, ya que los tiestos pueden ser examinados sin ser alterados o destruidos. Los análisis mediante RS y XRD se efectuaron en los laboratorios del Centro Atómico Constituyentes, Comisión Nacional de Energía Atómica (CNEA), Buenos Aires, Argentina.

El área analizada mediante XRD fue del orden del $\mathrm{cm}^{2}$. La adquisición de los datos se realizó en el rango de $10^{\circ}<2 \theta<70^{\circ}$, con paso $0,02^{\circ}$, empleando un equipo Panalytical, modelo Empyream con detector PIXCEL3D con monocromador y radiación de Cu (K-Alpha1 $[\AA]$ $=1,54060$ ). Se utilizó un tiempo de contaje de 2 segundos por paso. Para la identificación de fases presentes se empleó un programa denominado PC-Identify y la base de datos de la ICDD. Las mismas muestras fueron caracterizadas por espectroscopía Raman, utilizando espectrómetro LabRAM HR (Horiba Jobin Yvon) con doble monocromador y detector CCD de resolución espectral de $1,2 \mathrm{~cm}^{-1}$. El espectrómetro cuenta con enfoque microscópico: las áreas analizadas son del orden de entre 300 y $7500 \mu \mathrm{m}^{2}$ para los objetivos x 50 y x10, respectivamente. Como fuente excitadora, se utilizó la línea 514,5 nm de un láser de argón. Se mantuvo la potencia del láser baja para evitar el calentamiento y la degradación de la muestra.

En algunos casos se analizaron ambos lados del fragmento, es decir, tanto la superficie pigmentada como la no pigmentada. Esto posibilitó obtener información composicional de la matriz cerámica para compararla con las pinturas, con el fin de diferenciar los compuestos de la base arcillosa de aquellos utilizados en las mezclas pigmentarias.

Las muestras de pintura procedentes de los fragmentos $1,3,6$, 7, 8 y 9 (tabla 1 ) fueron examinadas, además, mediante la técnica de microscopía electrónica de barrido y microanálisis por dispersión de energía de rayos-X, en el marco de un trabajo previo (Ottalagano et al. 2015a). A diferencia de las técnicas RS y XRD que identifican las sustancias específicas empleadas en la elaboración de las pinturas, la técnica SEM-EDX recupera información sobre los elementos químicos presentes en ellas. Las dos primeras técnicas tienen una capacidad cualitativa de análisis, en tanto que esta última puede alcanzar un nivel semicuantitativo, indicando en qué proporción se encuentran los elementos identificados. Por ello, resulta provechoso combinar los datos aportados por todos estos procedimientos arqueométricos.

\section{RESULTADOS Y DISCUSIÓN}

En la tabla 2 se muestran los resultados comparativos de los compuestos químicos identificados mediante XRD y RS. Como se mencionó anteriormente, ambas técnicas aportan datos cualitativos, por lo que la tabla resume la presencia de las sustancias detectadas. Tanto XRD como RS no son aptas para definir en qué proporción se encuentra un compuesto en una pintura. Sin embargo, la medición de varios puntos con Rs en la superficie pintada permite tener una aproximación acerca de la abundancia o no de un compuesto en una mezcla pigmentaria. Puede observarse que en el caso de las pinturas rojas la sustancia colorante recurrente es la hematita $\left(-\mathrm{Fe}_{2} \mathrm{O}_{3}\right)$, la cual ha sido detectada en casi la totalidad de las muestras de esta tonalidad por una o ambas técnicas arqueométricas. A modo de ejemplo, en la figura 4 se presenta el difractograma obtenido sobre la muestra 10, donde se señalan los picos de hematita y cuarzo.

La hematita es un óxido férrico de tonos rojizos, muy difundido en la naturaleza, que ha sido ampliamente usado en el pasado como colorante. En la arqueología argentina se lo ha podido reconocer aplicado a distintos soportes, principalmente en el arte rupestre (e.g., Barbosa \& Gradin 1986-1987, Boschín et al. 2002, Podestá et al. 2008, Yacobaccio et al. 2008, Solá et al. 2013, Carden et al. 2014) y en la decoración cerámica (Bertolino et al. 2009, De la Fuente et al. 2010, Acevedo et al. 2012, Bugliani et al. 2012, Marte et al. 2012, Frère 2015, Freire et al. 2016), así como en cuero pintado (Solá et al. 2013). Además de su capacidad colorante, este mineral -al igual que los óxidos férricos en general- presenta la ventaja de ser muy resistente al intemperismo (Solá et al. 2013), volviéndose una materia prima idónea para preparaciones pigmentarias. La hematita ha sido reconocida también como un antiplástico frecuente en la pasta con la cual fueron elaboradas las alfarerías. Se la pudo detectar mediante microscopio petrográfico en la cerámica Goya-Malabrigo procedente de los sitios AAI, CPA, ALI y AAI (Ottalagano 2013a, 2015, 2016a), y ha sido registrada asimismo en la alfarería de numerosos sitios localizados en la cuenca del Paraná, asociados tanto a esta como a otras unidades arqueológicas (Loponte 2008, Pérez 2010, Tapia et al. 2013, Castiñeira et al. 2016).

La fuente de aprovisionamiento de este mineral es local. Cavallotto y colaboradores (2005) la identifican en la litología del delta del Paraná; por su parte Herbst 


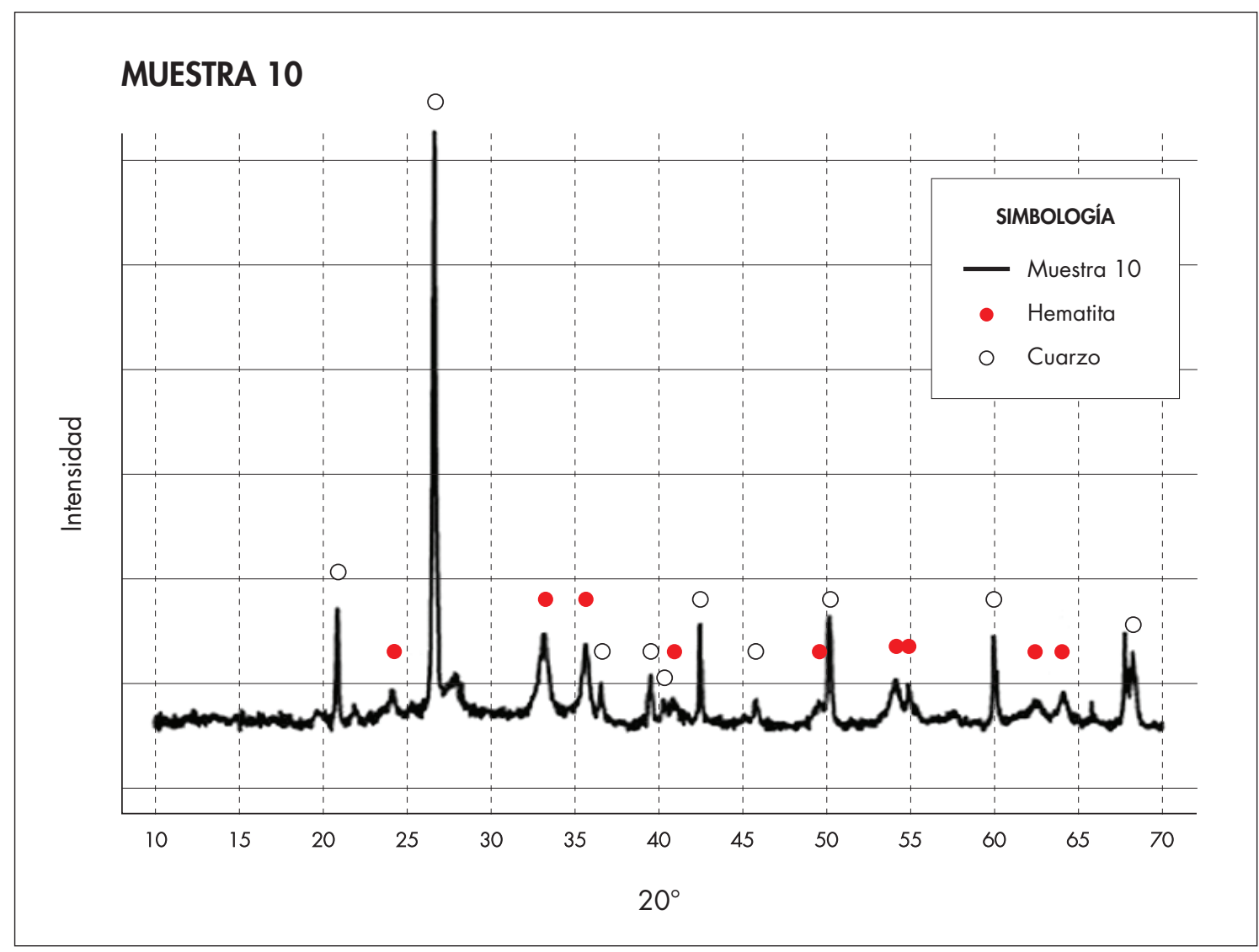

Figura 4: Difractograma de la muestra 10 de pintura roja (se señalan los picos de hematita, responsable del color rojo, y cuarzo). Figure 4. Diffractogram of red paint sample 10 (note the spikes of hematite, which provides the red color, and of quartz).

(2000), aunque no brinda detalles composicionales, señala la recurrencia de geodas ferruginosas en los sedimentos de la formación Ituzaingó, una formación sedimentaria de origen fluvial que se localiza a lo largo del todo el Paraná medio y en parte del Paraná inferior. La presencia de óxidos férricos en las pinturas rojas es corroborada por los análisis efectuados mediante EDX, en los que se revela la presencia de hierro ( $\mathrm{Fe}$ ) como uno de los componentes mayoritarios (tabla 3). Se constató que las pinturas rojas presentan en promedio $20 \%$ de contenido de hierro en su composición elemental, esto es 15\% más de Fe que aquel encontrado en la matriz cerámica y en las pinturas blancas (Ottalagano et al. 2015a).

En las muestras 7 y 9 se detectó además maghemita $\left(\gamma-\mathrm{Fe}_{2} \mathrm{O}_{3}\right)$, un óxido férrico menos común que la hematita (fig. 5), cuya tonalidad oscila entre el marrón oscuro y el rojo ladrillo, y que también es conocido por su poder colorante. La muestra 9 fue la única en que la hematita no pudo ser detectada; sin embargo, el contenido de Fe identificado por EDx, estaría asociado a la presencia de maghemita (tabla 2). En las muestras 8 y 9 se registró además grafito (tabla 2), el cual está generalmente vinculado con la elaboración de pinturas de color negro (Acevedo et al. 2012). En relación a esto, debe tenerse en cuenta que los espectros EDX de ambas muestras registran carbono $(\mathrm{C})$ en proporciones similares a las detectadas en la pasta de las alfarerías, sugiriendo que, en estos casos, el grafito sería constitutivo de la base arcillosa utilizada probablemente como vehículo de la pintura.

En cuanto a las pinturas blancas, los espectros EDX detectaron una significativa concentración de fósforo $(\mathrm{P})$ y calcio $(\mathrm{Ca})$ en dos de las tres muestras analizadas (Ottalagano et al. 2015a), sugiriendo que ambos elementos habrían formado parte esencial de las materias primas colorantes. Como hipótesis, se sostuvo 


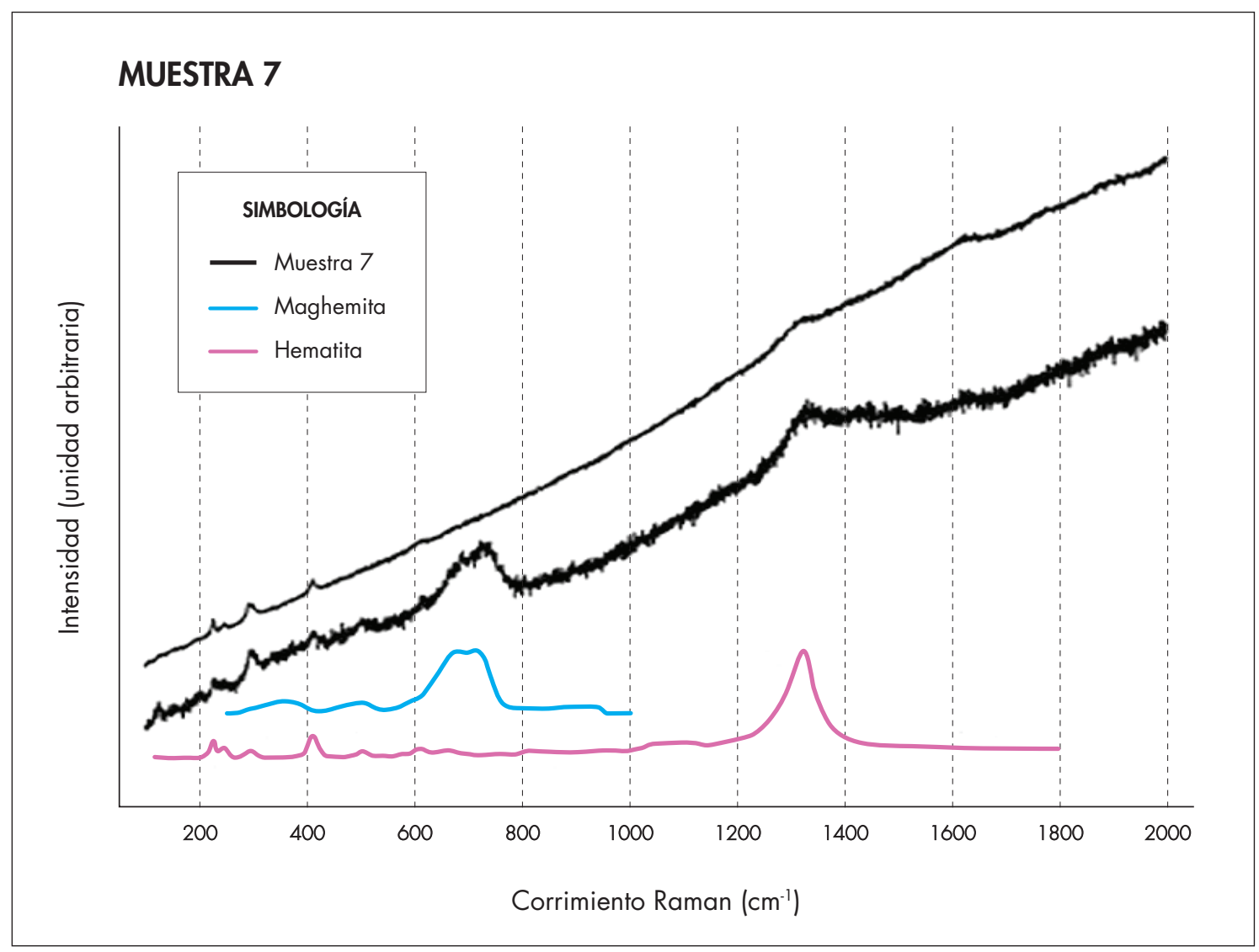

Figura 5. Espectros Raman de dos puntos diferentes de la muestra 7 de pintura roja (se observa en líneas coloreadas los espectros de maghemita y hematita de la base de datos). Figure 5. Raman spectra from two different sampling points on red paint sample 7 (the dotted lines are spectra for maghemite and hematite from the database).

que estos elementos podrían haber derivado de la presencia de hidroxiapatita o apatita orgánica $\left(\mathrm{Ca}_{5}\left(\mathrm{PO}_{4}\right)\right.$ $\mathrm{OH})$, el compuesto primordial con que están formados los huesos. La hidroxiapatita, que representa el uso de huesos calcinados y pulverizados, pudo ser reconocida como fuente de color blanco en pinturas cerámicas de diversas regiones (Marte et al. 2012, Frère 2015, Freire et al. 2016). Sin embargo, se carecía de datos que pudieran confirmar esta posibilidad en la alfarería de estilo GoyaMalabrigo. A partir de los análisis efectuados en este trabajo, se pudo constatar la presencia de hidroxiapatita en cuatro de las seis muestras de pintura blanca estudiadas (muestras 1, 2, 3 y 4), las cuales corresponden tanto a fragmentos de "campanas" como a restos cerámicos que no pertenecieron a estos peculiares artefactos (tablas 1 y 2). A modo de ejemplo, se detallan en la figura 6 los espectros Raman de la muestra 1 (fig. 6a) y el difractograma de la muestra 2 (fig. 6b). Cabe señalar que, al menos en una muestra de pintura blanca de cada uno de los cuatro sitios considerados aquí, se pudo relevar hidroxiapatita como fuente del color blanco (tablas 1 y 2). Su identificación fue registrada únicamente mediante XRD, lo cual se deba posiblemente al hecho de que esta técnica permite abarcar un área de análisis mayor que la espectroscopía Raman (ver apartado previo).

Particularmente en la muestra 2, correspondiente a un fragmento de recipiente "no campana", se observó hidroxiapatita también en la superficie sin pigmentar, aunque con una intensidad de señal relativa mucho menor que en aquella pigmentada (tabla 2). La identificación de hidroxiapatita en la superficie sin pigmentar podría estar asociada con factores contaminantes. En relación con esto último, se ha advertido la posible contaminación de los fragmentos por acumulación de minerales secundarios en los poros, por efecto del uso o a causa del contexto post-depositación (Cremonte \& 
Tabla 2. Compuestos identificados en las muestras. Table 2. Compounds identified in the samples.

\begin{tabular}{|c|c|c|c|}
\hline \multicolumn{2}{|c|}{ MUESTRAS } & RAMAN & XRD \\
\hline \multirow{8}{*}{ Pintura blanca } & $1^{*}$ & apatita, anatasa & cuarzo, hidroxiapatita, rutilo, rankinite, apatita \\
\hline & \multirow{2}{*}{2} & anatasa & $\begin{array}{l}\text { Superficie pigmentada: cuarzo, microclina, hidroxiapatita, labradorita, } \\
\text { feldespato de potasio, hematita }\end{array}$ \\
\hline & & & $\begin{array}{l}\text { Superficie sin pigmentar: cuarzo, rankinita, microclina, hidroxiapatita, } \\
\text { dolomita, illita }\end{array}$ \\
\hline & $3^{*}$ & anatasa & cuarzo, magnetita, hidroxiapatita, illita, dolomita, ortoclasa \\
\hline & 4 & anatasa & cuarzo, hidroxiapatita, esseneite, muscovita \\
\hline & 5 & anatasa & cuarzo, labradorita, rutilo, montmorillonita \\
\hline & \multirow{2}{*}{$6^{*}$} & anatasa, dolomita & $\begin{array}{l}\text { Superficie pigmentada: cuarzo, rankinita, rutilo, illita, anhidrita (yeso } \\
\text { seco), albita, muscovita }\end{array}$ \\
\hline & & & Superficie sin pigmentar: cuarzo, albita, muscovita, illita \\
\hline \multirow{7}{*}{ Pintura roja } & \multirow{2}{*}{$7^{\star}$} & hematita, maghemita & Superficie pigmentada: hematita, cuarzo, anortita \\
\hline & & & Superficie sin pigmentar: cuarzo, anortita, illita, dolomita \\
\hline & & anatasa, hematita & Superficie pigmentada: cuarzo, feitknechtite, rutilo, grafito \\
\hline & & & Superficie sin pigmentar: cuarzo, anortita, ilmenita, cristobalita \\
\hline & & maghemita, anatasa & Superficie pigmentada: jacobsita, rutilo, cuarzo, cristobalita, magnetita \\
\hline & & & Superficie sin pigmentar: cuarzo, rutilo, grafito, filipstadite, rodolicoite \\
\hline & 10 & hematita & cuarzo, hematita, labradorita \\
\hline
\end{tabular}

* Muestras que cuentan con análisis SEM-EDX.

Bugliani 2006-2009). Cabe señalar que los espectros EDX ya habían destacado una escasa presencia de $\mathrm{P}$ y Ca en la matriz cerámica, así como también en las pinturas rojas (Ottalagano et al. 2015a). La asociación de $\mathrm{P}$ y $\mathrm{Ca}$, como se dijo anteriormente, probablemente esté vinculada con la presencia de apatita orgánica. Sin embargo, los datos aportados por XRD no reportan hidroxiapatita en las pinturas rojas. Específicamente en la muestra 9, el hallazgo de $\mathrm{P}$ en mezcla pigmentaria roja sería compatible con la detección de rodolicoite $\left(\mathrm{FePO}_{4}\right)$ (tabla 2).

Las muestras 5 y 6 fueron las únicas en las cuales no se identificó hidroxiapatita como potencial fuente del color blanco, por lo cual la coloración de la pintura derivaría de otras sustancias. En la muestra 5 se reveló la presencia de montmorillonita $(\mathrm{Na}, \mathrm{Ca})_{0,3}(\mathrm{Al}, \mathrm{Mg})_{2} \mathrm{Si}_{4} \mathrm{O}_{16}(\mathrm{OH})_{2} \cdot \mathrm{xH}_{2} \mathrm{O}$, una arcilla que puede presentar una coloración gris-blanca y que está disponible localmente en los sedimentos de la formación Ituzaingó (Herbs 2000). En esta muestra no se cuenta por el momento con datos EDX que permitan discutir en qué proporción pudo estar presente este argilomineral. Asimismo, se detectó rutilo $\left(\mathrm{TiO}_{2}\right)$, un dióxido de titanio usado en la actualidad como base para elaborar un potente pigmento blanco. También se observa anatasa $\left(\mathrm{TiO}_{2}\right)$, otra de las formas con que aparece el dióxido de titanio, que también es blanco. La anatasa pudo identificarse mediante Raman en todas las muestras de pintura blanca y en dos de pintura 


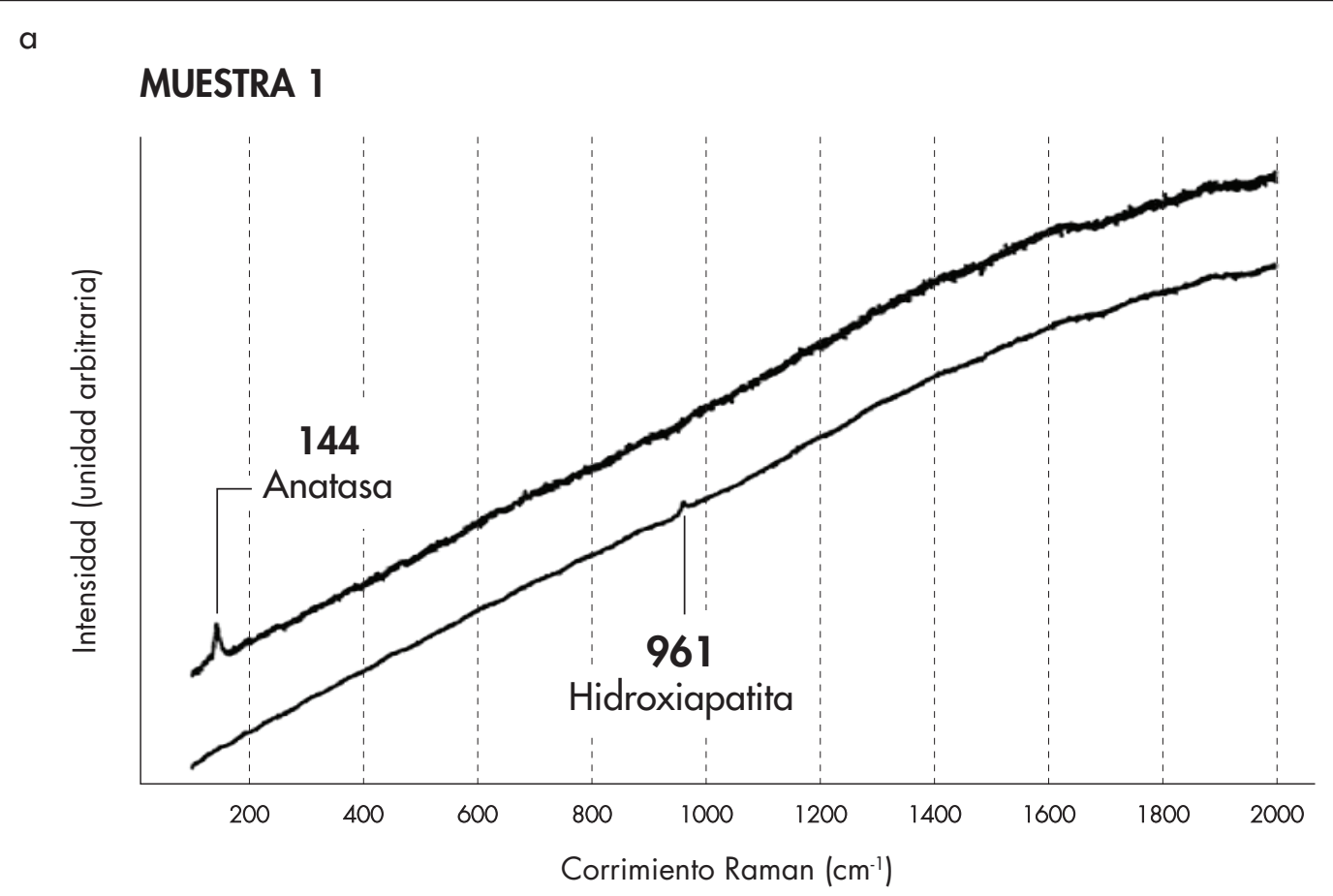

b

MUESTRA 2

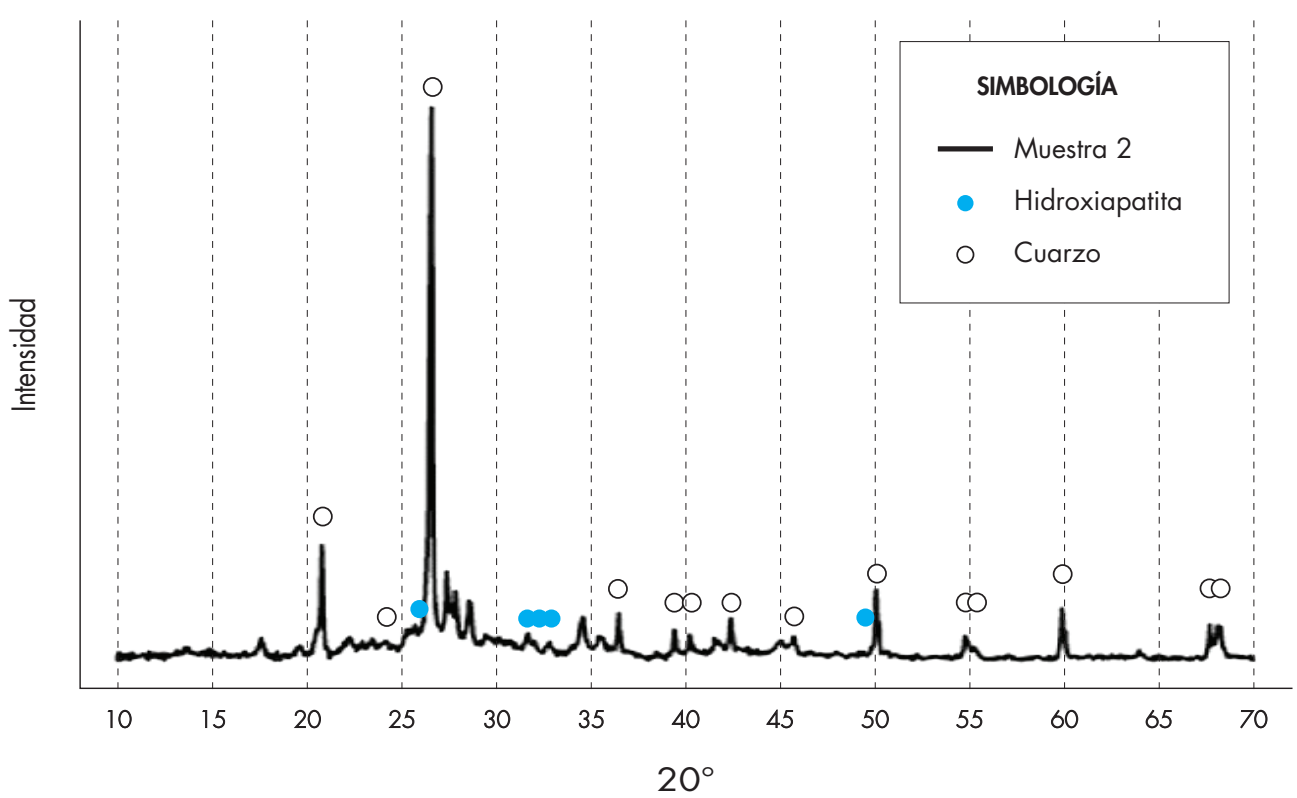

Figura 6. Análisis de pintura blanca: a) espectro Raman de dos puntos de la muestra 1, señalando los picos correspondientes a hidroxiapatita y anatasa; b) difractograma de la muestra 2, indicando los picos de hidroxiapatita y cuarzo. Figure 6. Analysis of white paint: a) Raman spectra for two points of sample 1, with the corresponding spikes for hydroxyapatite and anatase; $\boldsymbol{b}$ ) diffractogram of sample 2, with spikes for hydroxyapatite and quartz. 
Tabla 3. Mediciones EDX de algunas de las muestras analizadas (tomado y modificado de Ottalagano et al. 2015a). Table 3. EDX results for selected samples (modified from Ottalagano et al. 2015a).

\begin{tabular}{|c|c|c|c|c|c|c|c|c|c|c|c|c|c|c|c|}
\hline \multicolumn{2}{|c|}{ MUESTRAS } & \multirow{4}{*}{$\begin{array}{c}\text { MEDICIÓN } \\
\text { EDX } 1 \\
\text { EDX } 2\end{array}$} & \multicolumn{13}{|c|}{ COMPOSICIÓN ELEMENTAL (Wt. \%) } \\
\hline & & & \multirow{2}{*}{$\begin{array}{c}\text { C } \\
8.56\end{array}$} & 0 & $\mathrm{Na}$ & $\mathrm{Mg}$ & $\mathrm{Al}$ & $\mathrm{Si}$ & $\mathrm{P}$ & $\mathrm{Cl}$ & S & $\mathrm{K}$ & $\mathrm{Ca}$ & $\mathrm{Ti}$ & $\mathrm{Fe}$ \\
\hline \multirow{6}{*}{$\begin{array}{l}\text { Pintura } \\
\text { blanca }\end{array}$} & & & & 29,5 & - & - & 2,06 & 3,41 & 16,1 & 1,1 & - & 1,25 & 35,8 & - & 2,28 \\
\hline & & & 7,26 & 35,1 & - & - & 2,31 & 3,16 & 15,4 & 0,9 & - & 0,72 & 33,1 & - & 2,03 \\
\hline & 3 & EDX 1 & 8,67 & 22,3 & - & 2,62 & 4,63 & 12,7 & 7,24 & - & - & & 25,3 & - & 16,6 \\
\hline & & EDX 1 & 5,78 & 38 & - & 1,02 & 8,19 & 35,5 & - & - & - & 4,64 & 1,4 & 0,91 & 4,59 \\
\hline & 6 & EDX 2 & 3,33 & 39,1 & - & 1,22 & 8,37 & 36 & 0,76 & - & - & 4,57 & 2,09 & 0,86 & 3,78 \\
\hline & & EDX 3 & 12,1 & 37,1 & - & 1,01 & 8,49 & 28,6 & 1,11 & - & - & 4,64 & 1,66 & 0,77 & 4,46 \\
\hline \multirow{5}{*}{$\begin{array}{c}\text { Pintura } \\
\text { roja }\end{array}$} & 7 & EDX 1 & 4,05 & 27,5 & - & 0,55 & 4,61 & 13,9 & 0,46 & - & - & 0,71 & 0,85 & 0,3 & 47 \\
\hline & \multirow{2}{*}{9} & EDX 1 & 4,92 & 38,9 & - & 1,11 & 6,41 & 20,6 & 3,85 & - & - & 1,76 & 3,03 & 0,71 & 18,7 \\
\hline & & EDX 2 & 4,74 & 39,6 & - & 0,91 & 6,11 & 19,1 & 4,06 & - & - & 1,75 & 3,11 & 0,55 & 20,2 \\
\hline & \multirow{2}{*}{8} & EDX 1 & 4,61 & 35,4 & - & 0,53 & 8,49 & 28 & 2,7 & - & 0,25 & 3,2 & 1,38 & 0,86 & 14,6 \\
\hline & & EDX 2 & 12,5 & 36,6 & - & 0,4 & 6,78 & 29,5 & 1,75 & - & 0,32 & 2,35 & 1,5 & 0,61 & 7,66 \\
\hline \multirow{3}{*}{ Pasta } & 1 & EDX 4 & 5,08 & 35,8 & 1,09 & 1,24 & 9,8 & 22,7 & 6,41 & - & - & 4,32 & 6,92 & 1,08 & 5,6 \\
\hline & \multirow{2}{*}{3} & EDX 2 & - & 21,5 & - & 4,92 & 9,48 & 28,3 & - & - & - & 7,86 & 9,65 & - & 18,2 \\
\hline & & EDX 3 & - & 35,4 & - & - & 7,52 & 30,7 & 3,05 & - & - & 3,75 & 8,77 & - & 10,8 \\
\hline
\end{tabular}

roja, mientras que el rutilo aparece en igual número en pinturas blancas y rojas (tabla 2). Cabe señalar que los análisis mediante EDX no detectaron titanio (Ti) en las muestras 1 y 3 de pintura blanca, que son las que cuentan con los datos aportados por esta técnica (tabla 3). La falta de detección de Ti mediante EDx en las mismas podría estar vinculada con algún posible sesgo en los puntos analizados, los cuales representan áreas de estudio muy pequeñas, de entre 50 a $200 \mu \mathrm{m}$. También podría significar la posibilidad que el Ti sea parte de un compuesto accesorio, no relacionado con la fuente de color blanco.

En la muestra 6 se observan tres compuestos como potenciales fuente de color blanco: illita, anhidrita y dióxido de titanio en las fases rutilo y anatasa (tabla 2). La illita $\left(\mathrm{K}, \mathrm{H}_{3} \mathrm{O}\right)(\mathrm{Al}, \mathrm{Mg}, \mathrm{Fe})_{2}(\mathrm{Si}, \mathrm{Al})_{4} \mathrm{O}_{10}\left[(\mathrm{OH})_{2},\left(\mathrm{H}_{2} \mathrm{O}\right)\right]$ es otro mineral de arcilla que puede adquirir tonalidades grisblanco o plateado-blanco y que se encuentra igualmente presente en los sedimentos de la formación Ituzaingó. La detección de illita en la muestra 6 es concordante con los espectros EDX, en los cuales se observaron cantidades apreciables de silicio ( $\mathrm{Si}$ ) y aluminio (Al) (tabla 3). Las concentraciones de Si y Al de esta mezcla pigmentaria resultó similar a las halladas en la pasta de las alfarerías, lo que, en un trabajo previo, llevó a plantear que la fuente del color blanco provendría de la utilización de alguna arcilla de esta tonalidad (Ottalagano et al. 2015a). Los análisis mediante XRD no detectan caolinita, cuya incorporación a la mezcla pigmentaria se había esbozado originalmente como hipótesis, por ser una arcilla de gran blancura y de alto poder cubriente y adherente (Besoain 1985, Bartolomé 1997), que puede ser igualmente encontrada en los sedimentos locales (Herbst 2000).

Para la muestra 6, los difractogramas señalan, por otra parte, la presencia de anhidrita o sulfato de 
calcio anhidro $\left(\mathrm{CaSO}_{4}\right)$, conocido como yeso seco: un compuesto de tonalidad blanca a grisácea. Cuando se expone al agua, la anhidrita la absorbe y se transforma en sulfato de calcio dihidratado $\left(\mathrm{CaSO}_{4} 2 \mathrm{H}_{2} \mathrm{O}\right)$, el cual ha sido reconocido como fuente de color blanco en otros casos arqueológicos (Boschín et al. 2002, Palamarczuk \& Fernández de Rapp 2011). De acuerdo con los análisis EDX se puede apreciar, sin embargo, que el porcentaje de calcio, uno de los elementos básicos de la anhidrita, es mínimo en esta muestra, y que el azufre (S), otro de sus elementos constitutivos, no pudo ser detectado (tabla 3). Sin embargo, será necesario realizar nuevos análisis mediante EDX para descartar la existencia de algún posible sesgo en los puntos analizados por esta técnica. Por otro lado, según los espectros EDX, el Ti es un elemento escaso en esta muestra (tabla 3 ), verificándose en proporciones similares a las encontradas en la pasta (Ottalagano et al. 2015a); sugiriendo, por lo tanto, que el dióxido de titanio sería un compuesto accesorio, derivado probablemente de las sustancias arcillosas. Estos datos refuerzan la idea, entonces, de que la fuente de color blanco de la muestra 6 provendría de la utilización de illita.

La illita fue identificada, asimismo, en la composición de la pintura blanca correspondiente a la muestra 3 (tabla 2). Sin embargo, la proporción de este compuesto en esta mezcla pigmentaria probablemente sea radicalmente menor que en la muestra 6 , ya que se observan comparativamente menores cantidades de Al y Si (tabla 3).

Tanto en las pinturas blancas como en las rojas se observaron además otros compuestos, que probablemente no habrían estado vinculados con la fuente del color de las pinturas, y que serían atribuibles al material arcilloso. Se relevó principalmente cuarzo $\left(\mathrm{SiO}_{2}\right)$ y varias clases de feldespatos como anortita $\left(\mathrm{CaAl}_{2} \mathrm{Si}_{2} \mathrm{O}_{8}\right)$, labradorita $\left.(\mathrm{Ca}, \mathrm{Na})(\mathrm{Si}, \mathrm{Al})_{4} \mathrm{O}_{8}\right)$ o feldespatos de potasio $\left(\mathrm{KAlSi}_{3} \mathrm{O}_{8}\right)$, como ortoclasa y microclina (tabla 2), cuya presencia es frecuente en la pasta de las alfarerías de los sitios arqueológicos considerados en este trabajo (Ottalagano 2013a, 2015, 2016a). Se identificaron también compuestos de calcio, como apatita $\mathrm{Ca}_{5}\left(\mathrm{PO}_{4}\right)_{3}(\mathrm{~F}, \mathrm{Cl}, \mathrm{OH})$ y dolomita $\left(\mathrm{CaMg}\left(\mathrm{CO}_{3}\right)_{2}\right)$, así como los óxidos feitknechtite $\left(\mathrm{MnO}(\mathrm{OH})\right.$ y magnetita $\left(\mathrm{Fe}_{3} \mathrm{O}_{4}\right)$; esta última también identificada mediante técnica petrográfica en la pasta cerámica de los sitios LPII, AAI y CPA (Ottalagano 2013a, 2015, 2016a).

\section{CONCLUSIONES}

El uso combinado de RS y XRD, por primera vez aplicado a la cerámica monocroma de estilo Goya-Malabrigo, permitió identificar los compuestos químicos inorgánicos presentes, aportando más información sobre la composición de las mezclas pigmentarias. Los datos recabados señalan a la hematita como la sustancia colorante utilizada recurrentemente en la preparación de la pintura roja. La hematita es reconocida habitualmente en la pasta de las alfarerías de la cuenca media e inferior del Paraná (Loponte 2008, Pérez 2010, Tapia et al. 2013, Ottalagano 2013a, 2015, 2016a, Castiñeira et al. 2016), y es una materia prima disponible localmente. Dos de las muestras rojas recuperadas en el sitio AAI registraron también maghemita, otro óxido férrico que, al igual que la hematita, es conocido por su alto poder colorante. La presencia de Fe como componente mayoritario en las pinturas rojas fue inicialmente establecida por los análisis efectuados mediante EDx, donde se revela que la proporción de Fe en estas pinturas sería en promedio de un $20 \%$, con porcentajes que oscilan entre el 7,6\% y el 47\% (Ottalagano et al. 2015a).

En las pinturas blancas el principal pigmento registrado es la hidroxiapatita, sugiriendo el empleo de huesos calcinados y pulverizados. Este compuesto está presente en cuatro de las seis muestras analizadas, las cuales proceden de los distintos sitios arqueológicos considerados (AAI, ALI, LPAII y CPA). Cabe señalar que la presencia de hidroxiapatita en la pintura blanca se detectó tanto en "alfarerías gruesas" como en un fragmento de recipiente, probablemente de morfología abierta.

En las dos muestras blancas restantes, en las cuales no fue posible registrar hidroxiapatita, se identificaron dos minerales de arcilla como potenciales fuentes de color: illita y montmorillonita. Ambas arcillas, cuyas tonalidades suelen ser gris-blanco, presentan una disponibilidad local, ya que pueden ser encontradas en la formación Ituzaingó (Herbst 2000). La illita se comprobó en una muestra de "alfarería gruesa" recuperada en el sitio LPII, en tanto que la montmorillonita se registró en un recipiente de morfología indeterminada procedente del sitio AAI. Otros compuestos detectados, que podrían también ser considerados potenciales fuentes de color blanco son: la anhidrita o yeso seco y el dióxido de titanio, en las fases rutilo y anatasa. Los espectros EDX sugieren que estos compuestos se habrían encontrado presentes en escasa proporción en las muestras analizadas, por lo 
que se estima que se trataría de sustancias accesorias, atribuibles a las materias primas arcillosas. Sin embargo, se procurará efectuar nuevos estudios mediante EDX para descartar la existencia de algún posible sesgo en los puntos analizados por esta técnica.

Los resultados obtenidos en este trabajo permiten ampliar los conocimientos sobre la tecnología cerámica de estilo Goya-Malabrigo en el Paraná medio e inferior $y$, en especial, acerca de las elecciones tecnológicas implementadas por los alfareros durante la etapa final de la elaboración de una vasija, permitiendo contar con una base de información con la cual establecer luego comparaciones regionales. A fin de evaluar las potenciales fuentes de abastecimiento de las materias primas utilizadas, se espera a futuro realizar análisis físico-químicos en muestras arcillosas y pigmentos rojos tomados en distintos afloramientos naturales de la cuenca del río Paraná. Esto permitirá correlacionar los datos composicionales de las mezclas pigmentarias con aquellos de los bancos sedimentarios locales, lo que posibilitará valorar la eventual procedencia de los materiales utilizados, así como su distancia de aprovisionamiento.

Agradecimientos María Reinoso y Eleonora Freire agradecen la financiación de CONICET (PIP-0660CO).

\section{NOTAS}

${ }^{1}$ A diferencia de la pintura, que es concebida como una técnica decorativa, el engobe se lo considera generalmente como un acabado de superficie que suele aplicarse por inmersión o por untamiento de la pieza en una mezcla de agua y arcilla (Convención Nacional de Antropología 1966). Sin embargo, en caso de incorporarse algún colorante a la mezcla, este podría ser confundido con una pintura pre-cocción.

\section{REFERENCIAS}

Acevedo, V., López, M., Freire, E., Halac, E., Polla, G. \& Reinoso, M. 2012. Estudio de pigmentos en alfarería estilo negro sobre rojo de quebrada de Humahuaca, Jujuy, Argentina. Boletín del Museo Chileno de Arte Precolombino 17 (2): 39-51.

Aldazabal, V., Silveira, M., Custo, G. \& Ortiz, M. 2014. Colores al norte del lago Traful, Neuquén. Boletín del Museo Chileno de Arte Precolombino 19 (2): 95-105.

BAвот, M. P. \& Apella, M. C. 2007. Aproximación al proceso de producción de alfarería en el área valliserrana de Tu- cumán, Argentina: un análisis de mezclas pigmentarias y coberturas cerámicas. En Cerámica arqueológica, perspectivas arqueométricas para su análisis e interpretación, M. B. Cremonte \& N. Ratto, Eds., pp. 13-26. San Salvador de Jujuy: EdiUnju.

Barbosa, C. E. \& Gradin, C. J. 1986-87. Estudio composicional por difracción de rayos-X de los pigmentos provenientes de la excavación del Alero Cárdenas (Provincia de Santa Cruz). Relaciones de la Sociedad Argentina de Antropología 17 (1): 143-171.

BARTolomé, J. F. 1997. El caolín: composición, estructura, génesis y aplicaciones. Boletín de la Sociedad Española de Cerámica y Vidrio 36 (1): 7-19.

Bertolino, S., Galván Josa, V., Carreras, A., Laguens, A., De la Fuente, G. \& Riveros, J. 2009. X-ray techniques applied to surface paintings of ceramic pottery pieces from Aguada Culture (Catamarca, Argentina). X-Ray Spectrometry 38: 95-102.

Besoain, E. 1985. Mineralogía de arcillas de suelos. San José: CIDIA-IICA.

Boschírn, M. T., Seldes, A. M., Maier, M., Casamiquela, R., Ledesma, R. \& AbAd, G. 2002. Análisis de las fracciones inorgánica y orgánica de pinturas rupestres y pastas de sitios arqueológicos de la Patagonia Sseptentrional argentina. Zephyrus 55: 183-198.

Botto, I., Barone, V., Cremonte, M. B. \& SÁnchez, M. A. 1998. Estudios arqueométricos de cerámicas provenientes del Noroeste Argentino. Información Tecnológica 9 (6): 79-86.

Bouza, P., Gómez Otero, J., Taylor, R., Schuster, V. \& Melatini, M. S. 2007. Tecnología de cerámicas arqueológicas en el nordeste de la Provincia de Chubut. Pacarina 3: 447-452.

Bugliani, M. F., Di Lello, C., Freire, E., Polla, G., Petragalli, A., Reinoso, M. \& Halac, E. 2012. Empleo de espectroscopía Raman, difracción de rayos X y microscopia electrónica para el análisis de pigmentos en cerámicas Vaquerías. Boletín del Museo Chileno de Arte Precolombino 17 (2): 65-74.

Caggiano, M. A. 1984. Prehistoria del N.E. Argentino. Sus vinculaciones con la República Oriental del Uruguay y sur de Brasil. Pesquisas Antropología 38: 5-109.

Carden, N., Blanco, R., Poiré, D., Genazzini, C., Magnin, L. \& García, P. 2014. Análisis de pigmentos del macizo del Deseado: el abastecimiento de materias primas y la producción de pinturas rupestres en cueva Maripe (Santa Cruz, Argentina). Relaciones de la Sociedad Argentina de Antropología 39 (2): 483-508.

Castiñeira latorre, C., Di Lello, C. \& Blasi, A. 2016. Explotación y manejo del recurso sedimentario/ pedológico por los constructores de cerritos del delta superior del río Paraná y litoral fluvial de Gualeguaychú-Argentina. Intersecciones en Antropología 3: 7-21.

Cavallotto, J. L., Violante, R. \& Colombo, F. 2005. Evolución y cambios ambientales de la llanura costera de 
la cabecera del Río de la Plata. Revista de la Asociación Geológica Argentina 60 (2): 353-367.

Ceruti, C. 1989 Ms. Las modificaciones ambientales del Pleistoceno final-Holoceno y su relación con los asentamientos humanos en el noroeste de Entre Ríos. Informe final arqueológico PID-CONICET No 3-081800/88.

Ceruti, C. 2003. Entidades culturales presentes en la cuenca del Paraná medio (margen entrerriana). Mundo de Antes 3: 111-135.

Convención Nacional de Antropología. 1966. Primera Convención Nacional de Antropología. Córdoba: Universidad Nacional de Córdoba.

Cremonte, M. B., Baldini, M. \& Botto, I. 2003. Pastas y colores. Un camino al conocimiento del estilo Portezuelo de Aguada. Intersecciones en Antropología 4: 3-16.

Cremonte, M. B. \& Bugliani, M. F. 2006-2009. Pasta, forma e iconografía. Estrategias para el estudio de la cerámica arqueológica. Xama 19-23: 239-262.

De la Fuente, G., Carreras, A., Pérez, J. M., Martín, S. \& Riveros, A. 2010. Identificación y análisis de pigmentos y pinturas en cerámicas arqueológicas Sanagasta (ca. AD 900 - AD 1200) e Inka (ca. AD 1480 - AD 1532) a través de MEB-EDS y microespectroscopía de Raman (Abaucán, Tinogasta, Catamarca, Argentina). En La arqueometría en Argentina y Latinoamérica, S. Bertolino, R. Cattáneo \& A. Izeta, Eds., pp. 325-331. Córdoba: Editorial de la Facultad de Filosofía y Humanidades, UNC.

Freire, E., Acevedo, V., Halac, E., Polla, G., López, M. \& Reinoso, M. E. 2016. X-ray diffraction and Raman spectroscopy study of white decorations on tricolored ceramics from Northwestern Argentina. Spectrochimica Acta Part A: molecular and biomolecular spectroscopy 157: 182-185.

Frère, M. M. 2015. Tecnología cerámica de los cazadores-recolectores-pescadores de la microrregión del Río Salado, Provincia de Buenos Aires. Tesis para optar al título de Doctor, Facultad de Filosofía y Letras, Universidad de Buenos Aires.<https://www.academia.edu/21799809/ TECNOLOG\%C3\%8DA_CER\%C3\%81MICA_DE_ LOS_CAZADORES-RECOLECTORES-PESCADORES_DE_LA_MICRORREGI\%C3\%93N_DEL_R\%C3\%8DO_SALADO_PROVINCIA_DE_BUENOS_AIRES $\geq$ [consultado: 25-06-2019].

García, J. \& Calvo, M. 2013. Making pots. El modelado de la cerámica a mano y su potencial interpretativo. Oxford: British Archaeological Reports, International Series 2540.

Gómez, J., Alric, V. \& TAYlor, R. 1996. Una nueva forma cerámica del Chubut: análisis mineralógicos y experiencias de reproducción. En Arqueología, solo Patagonia, J. Gómez Otero, Ed., pp. 349-358. Puerto Madryn: Centro Nacional Patagónico, Conicet.

GonzÁlez, A. R. 1977. Arte precolombino de la Argentina. Introducción a su historia cultural. Buenos Aires: Imprenta Coni.
GonzÁlez, M. I. 2005. Arqueología de alfareros, cazadores y pescadores pampeanos. Buenos Aires: Sociedad Argentina de Antropología.

GonZÁLEZ de BonAVERI, M. I. \& Frère, M. M. 2002. Explorando algunos usos de la alfarería pampeana. En Del mar a los salitrales, diez mil años de historia pampeana en el umbral del tercer milenio, D. Mazzanti, M. Berón \& F. Oliva, Eds., pp. 31-40. Mar del Plata: Universidad de Mar del Plata.

GonZÁlez de Bonaveri, M. I. \& Frère, M. M. 2004. Analysis of potsherds residues and vessel use in hunter-gatherer-fisher groups (Pampean Region, Argentina). En Actas del XIV th UISPP Congress, University of Liege, Le Secrétariat du Congres, Ed., pp. 27-36. Oxford: BAR International Series 1270.

Herbst, R. 2000. La Formación Ituzaingó (Plioceno). Estratigrafía y distribución. Serie Correlación Geológica 14:12. <http://www.insugeo.org.ar/publicaciones/docs/ scg_14/12_la_formacion_ituzaingo.htm $>$ [consultado: 26-03-2015].

López, M., De la Fuente, G. \& Fiore, D. 2012. Arqueometría del arte: estudios fisicoquímicos de pigmentos arqueológicos. Boletín del Museo Chileno de Arte Precolombino 17: 75-81.

Loponte, D. 2008. Arqueología del humedal del Paraná inferior: bajíos ribereños meridionales. Buenos Aires: Instituto Nacional de Antropología y Pensamiento Latinoamericano.

Marte, F., Acevedo, V. \& Mastrangelo, N. 2012. Técnicas arqueométricas combinadas aplicadas al análisis de diseños de alfarería "tricolor" de quebrada de Humahuaca, Jujuy, Argentina. Boletín del Museo Chileno de Arte Precolombino 17 (2): 53-64.

Matarrese, A., Di Prado, V. \& Poirè, D. 2011. Petrologic analysis of mineral pigments from hunter-gatherers archaeological contexts (Southeastern Pampean region, Argentina). Quaternary International 245: 2-12.

Munsell Color. 1994. Munsell soil color chart. Nueva York: Macbeth Division of Kollmorgen.

Ottalagano, F. 2013a. The pre-Hispanic ceramic technology of South American hunter-gatherers (Paraná River Delta, Argentina): a preliminary archaeometric study. Archaeological and Anthropological Sciences 5: 59-68.

Ottalagano, F. 2013b. Aves simbólicas, estilo e identidad en la arqueología del gran río sudamericano: un estudio contextual del arte cerámico de las sociedades prehispánicas de la cuenca del río Paraná (Arqueología de la cuenca del Plata, serie monográfica). Buenos Aires: Instituto Nacional de Antropología y Pensamiento Latinoamericano.

Ottalagano, F. 2015. Explorando la variabilidad petrográfica entre vasijas decoradas y lisas del sitio La Palmera 2 (Entre Ríos, Argentina): hacia un abordaje microscópico del arte cerámico prehispánico de la cuenca del río Paraná. Revista Chilena de Antropología 32 (2): 21-38.

Ottalagano, F. 2016a. A diachronic study of pre-Hispanic vessels from the middle basin of Paraná River (South America) using a petrographic approach. Journal of Archaeological Science: Reports 9: 320-329. 
Ottalagano, F. 2016b. Investigaciones arqueológicas en el sitio Arroyo Arenal I: cuenca media del río Paraná (Entre Ríos, Argentina). Cuadernos del Instituto Nacional de Antropología y Pensamiento Latinoamericano 25 (2): 159-176.

Ottalagano, F., Domínguez, S. \& Bozzano, P. 2015a. Arqueología de los colores: análisis MEB-EDX de mezclas pigmentarias en cerámicas prehispánicas de la cuenca del río Paraná (provincia de Entre Ríos, nordeste de Argentina). Boletín del Museo Chileno de Arte Precolombino 20 (2): 57-68.

Ottalagano, F., Darigo, M., Pereyra, B., Brancatelli, C. \& IANNELLI, L. 2015b. Investigaciones arqueológicas en el sitio La Palmera 2 (cuenca del Paraná medio, provincia de Entre Ríos, nordeste de Argentina). Revista de Antropología del Museo de Entre Ríos 1 (1): 55-65.

Ottalagano, F., Darigo, M., Sulich, K. \& Arelovich, L. 2010. Investigaciones arqueológicas en el Delta superior entrerriano: sitio Cerro Puesto Acosta (Departamento Victoria, Provincia de Entre Ríos). En Arqueología argentina en el bicentenario de la Revolución de Mayo, R. Bárcena \& H. Chiavazza, Eds., pp. 1475-1480. Mendoza: Universidad Nacional de Cuyo.

Palamarczuk, V. \& Fernández De Rapp, M. E. 2011. Nuevos análisis sobre el relleno blanco decorativo de la alfarería Famabalasto Negro Grabado (Períodos Tardío e Incaico, Noroeste Argentino). En Actas del II Congreso Latinoamericano de Arqueometría, L. Vetter, R. Vega, P. Olivera \& S. Petrick, Eds., pp. 125-136. Lima: Editorial Universitaria de la Universidad Nacional de Ingeniería.

Paleo, M. C. \& Pérez, M. 2009. Relación-forma función en un conjunto alfarero del Partido de Magdalena, Provincia de Buenos Aires: una aproximación metodológica. En Problemáticas de la arqueología contemporánea, A. Austral \& M. Tamagnini, Eds., Tomo 2, pp. 219-226. Río Cuarto: Universidad Nacional de Río Cuarto.

Pedrotta, V. 2011. Avances en el estudio de pigmentos minerales: el caso de las sierras de Curicó (Tandilia, Región Pampeana, Argentina). Cazadores Recolectores del Cono Sur 4: 175-186.<https://ri.conicet.gov.ar/handle/11336/28228 2 [consultado: 25-06-2019].

Pérez, M. 2010. Tecnología de producción de la alfarería durante el Holoceno Tardío en el humedal del Paraná inferior. Un estudio petrográfico. Tesis para optar al grado de Licenciada en Ciencias Antropológicas. Facultad de Filosofía y Letras, Universidad de Buenos Aires.

Pérez, M., Ali, S., Bozzano, P. \& Domínguez, S. 2015. Pigmentos de la cerámica del humedal del Paraná inferior: análisis físico-químico MEB-EDX. Trabajo presentado en el vi Encuentro de discusión de arqueología del nordeste argentino, Gualeguaychú, Argentina. <https:// www.academia.edu/15998630/Pigmentos_de_la_ cer\%C3\%A1mica_del_humedal_del_Paran\%C3\%A1_inferior_an\%C3\%A1lisis_f\% $3 \% \mathrm{ADsico}-q u \% \mathrm{C} 3 \% \mathrm{ADmico}$ MEB-EDX> [consultado: 25-06-2019].
Petit, J. \& Valot, H. 1991. Glossaire des peintures et vernis: des substances naturelles et des matériaux synthétiques. Saint-Etienne: SFIIC-ARAAFU-IFROA.

Podestá, M. M., Bellelli, C., Labarca, R., Albornoz, A., Vasini, A. \& Tropea, E. 2008. Arte rupestre en pasos cordilleranos del bosque andino patagónico (El Manso, Región de Los Lagos y provincia de Río Negro, ChileArgentina). Magallania 36 (2): 143-153.

Porto, J. \& Mazzanti, D. 2009. Pigmentos minerales arqueológicos y fuentes de aprovisionamiento del sudeste bonaerense: análisis arqueométrico comparativo. Arqueometría Latinoamericana, 2do. Congreso Argentino, 1 ro. Latinoamericano 1: 215-220. Buenos Aires: CNEA-UNSAM.

Rial, G. \& BARbosa, C. 1983-1985. Análisis mineralógico por difracción de rayos $\mathrm{X}$ de muestras de pinturas del cerro Casa de Piedra, sitio CCP5 (Provincia de Santa Cruz, República Argentina). Cuadernos del Instituto Nacional de Antropología 10: 307-311.

Rodríguez, J. 1992. Arqueología del sudeste de Sudamérica. En Prehistoria sudamericana. Nuevas perspectivas, B. Meggers, Ed., pp. 177-209. Washington-Santiago de Chile: Taraxacum.

Rye, O. 1981. Pottery technology. Washington: Taraxacum.

Schuster, V. 2010. Diferentes técnicas para el mismo problema: el estudio tecnológico de un conjunto cerámico fragmentario (costa nordeste del Chubut, Patagonia Argentina). Comechingonia Virtual 4 (1): 1-26.

Serrano, A. 1946. Arqueología del arroyo Las mulas en el noroeste de Entre Ríos. Córdoba: Universidad de Córdoba.

Serrano, A. 1958. Manual de cerámica indígena. Córdoba: Assandri.

SHEPARD, A. 1963. Ceramics for the archaeologist. Washington: Carnegie Institution of Washington.

Solá, S., Yacobaccio, H., Rosenbusch, M., Alonso, M. S., Maier, M., VÁzquez, C. \& CATÁ, M. P. 2013. Hematita vs. arcillas: su potencial como pigmentos rojos y su uso en tres sitios de la puna jujeña (Argentina). Boletín del Museo Chileno de Arte Precolombino 18 (1): 67-83.

TAPiA, A., SolÁ, P. \& Rosenbusch, M. 2013. Efectos posdepositacionales en la cerámica del sitio Rancho José, Baradero, Provincia de Buenos Aires. En Arqueometría argentina. Estudios pluridisciplinarios, M. Ramos, M. Lanza, V. Helfer, V. Pernicone, F. Bognanni, C. Landa, V. Aldazabal \& M. Fernández, Eds., pp. 1-14. Luján: Aspha.

Yacobaccio, H., Catá, M. P., Solá, P. \& Alonso, M. S. 2008. Estudio arqueológico y fisicoquímico de pinturas rupestres en Hornillos 2 (Puna de Jujuy). Estudios Atacameños 36: 5-28.

Zagorodny, N., Balesta, B., Zalba, P. \& Morosi, M. 2002. La confección de pigmentos en la producción de cerámica arqueológica (La Aguada, Catamarca, Argentina). Relaciones de la Sociedad Argentina de Antropología 27: 177-192. 